\title{
TCOM \\ Exploring the digital media ecology: insights from a study of healthy diets and climate change communication on digital and social media
}

\section{Emma Weitkamp, Elena Milani, Andy Ridgway and Clare Wilkinson}

\begin{abstract}
This study explores the types of actors visible in the digital science communication landscape in the Netherlands, Serbia and the U.K. Using the Koru model of science communication as a basis, we consider how science communicators craft their messages and which channels they are using to reach audiences. The study took as case studies the topics of climate change and healthy diets to enable comparison across countries, topics and platforms. These findings are compared with the results from a survey of over 200 science communication practitioners based in these countries. We find that although traditional media are challenged by the variety of different new entrants into the digital landscape, our results suggest that the media and journalists remain highly visible. In addition, our survey results suggest that many science communicators may struggle to gain traction in the crowded digital ecology, and in particular, that relatively few scientists and research institutions and universities are achieving a high profile in the public digital media ecology of science communication.
\end{abstract}

Keywords

DOI

Introduction
Environmental communication; Health communication; Science and media https://doi.org/10.22323/2.20030202

Submitted: 10th November 2020

Accepted: 24th February 2021

Published: 10th May 2021
Recent decades have seen tremendous change in the way that people consume scientific information and it has been argued that journalists and media organisations are no longer the 'principle arbiters of what scientific information enters the public domain and how it does' [Trench, 2007, p. 141; also Pearce et al., 2019]. Today, people access scientific content on media as diverse as the image-based platform Instagram, the microblogging site Twitter, organisational websites and the websites of legacy media. With the growing diversity of digital platforms has come an increasing diversity of communicators, and it is now possible for anyone to enter the communications fray [see e.g. Bruns, 2008], including organisations (such as research institutes, governments and museums) seeking to reach publics directly [Koivumäki and Wilkinson, 2020], as well as 
individuals such as scientists, activists and a range of interested 'non-professionals' in the context of science communication. In this digital context, 'audiences are turning into active participants' [Schäfer, 2017, p. 52] in public discourses on scientific issues, and thus, those who we might previously have thought of as consumers of news and information about science, may now comment and contribute to this discourse, leading to a digital media ecology for science that is 'pluralistic, participatory and social' [Fahy and Nisbet, 2011, p. 778]. This paper explores the landscape of this digital media ecology for science communication, with a focus on three European countries as case studies: The Netherlands, Serbia and the U.K. It builds on previous work suggesting an expansion in the range of actors contributing to the digital science communication landscape, and seeks to clarify this landscape through a systematic characterisation of two discourses: climate change and healthy diets.

Digital media encompass a wide variety of sources for science communication. Murthy [2018] points to the distinction between different types of digital media, including social networks, social media and microblogging. Murthy defines social networks as based around friendship maintenance (e.g. Facebook), while social media are considered to be more akin to broadcast media (e.g. Twitter and Instagram) where the intention is to broadcast information to unknown users. Research into science communication via digital and social media is developing [Brossard, 2013; Wilkinson and Weitkamp, 2016; Davies and Hara, 2017; Hargittai, Füchslin and Schäfer, 2018], but Pearce et al. [2019] highlight a dominance of studies focusing on Twitter at the expense of other social media platforms.

Davies and Hara [2017] highlight the complexity of the digital sphere, with many gaps in what we know about science communication online. This online digital media sphere is important because many members of the public are increasingly finding out about science through these platforms rather than legacy media [Kantar, 2020]. Furthermore, Scheufele and Krause [2019] suggest that many readers are unable to identify potential bias in social media coverage of science news. They argue that increasing public attention [has been brought] to the role of social media in structuring and presenting information in such a way that may limit an individual's ability to assess the quality and usefulness of information, and to distinguish between fact and fiction' [Scheufele and Krause, 2019, p. 7664]. While we acknowledge that the flow of information in social media occurs in many ways, we argue that it is important to know what information achieves high visibility in the digital media ecology and which actors are communicating this information.

The 'pluralization of public communication' [Schäfer, 2017, p. 52, italics original] has led to a declining role for professional gatekeepers, such as journalists, and the inclusion of more diverse voices. Along with this has come a wider array of perspectives on scientific topics, particularly controversial ones. Research into digital science communication has tended to focus either on specific communicator groups, e.g. scientists [Petersen, Vincent and Westerling, 2019; Collins, Shiffman and Rock, 2016; Wilkinson and Weitkamp, 2013] and journalists [Fahy and Nisbet, 2011; Schäfer and Painter, 2021], or on particular digital media platforms [e.g Milani, Weitkamp and Webb, 2020; Pavelle and Wilkinson, 2020; Saboia et al., 2018; Su et al., 2017; Muñoz Morcillo, Czurda and Robertson-von Trotha, 2016; Spartz et al., 2017]. Studies of scientists and researchers suggest some limited presence 
online, with a focus on platforms such as Twitter [Koivumäki and Wilkinson, 2020; Collins, Shiffman and Rock, 2016].

Questions arise about the role of social media in providing a space where new types of opinion leaders can have access to a range of new publics, potentially reducing the role of gatekeeper traditionally afforded to journalists. This could have a democratising effect [Koivumäki and Wilkinson, 2020], opening up spaces for new types of communicators to contribute to online science discourses. In the context of Twitter, Murthy [2018] points out that whether Twitter is democratising depends on who is able to achieve the status of influencer, or opinion leader, and whether this includes groups who would not traditionally be able to access legacy media. Fahy and Nisbet [2011] point to the way in which changes in the media landscape have enabled new voices to contribute to public understanding of scientific controversy, allowing for example, scientists to have debates in public through media such as blogs and Twitter. Thus, there is a 'changing environment where journalists and scientists, readers and critics, professionals and amateurs, are simultaneously science content producers and audiences' [Fahy and Nisbet, 2011, p. 780].

Few studies have specifically looked at the breadth of different types of communicators within a public scientific discourse. In the context of palaeontology, Bex, Lundgren and Crippen [2019] identified a wide range of different groups contributing to discussion on Twitter. This included a range of different scientific expertises, publics with a particular interest, commercial members selling goods and services, and artists spotlighting their creations. In a similar study, researchers were found to be the primary source of original tweets about scientific papers, except in the area of life sciences where civil society organisations were the largest tweet initiators, and in the area of physics and engineering where journal publishers were the largest initiators of tweets [Didegah, Mejlgaard and Sørensen, 2018]. Pearce et al. [2019] argue there is a need to explore a wider range of platforms which are used by science communicators. Thus, we aim to contribute to the scant literature on online science communication [Scheufele and Krause, 2019] and address the following questions:

1) What types of content producers are visible in the new media ecology of science communication, and do these vary between case study countries or between case study topics?

2) Which platforms are used to communicate about climate change and healthy diets in each of the case study countries?

In addressing these questions, we seek to provide a view of the online science communication ecosystem that more accurately reflects what would be seen by online users than studies of one or a small number of platforms would afford. We applied the Koru model of science communication [Longnecker, 2016] to consider our results across two distinct areas. In this context we see science communicators as crafting messages that are designed to increase the likelihood that information will be noticed, will be seen as relevant and will be readily understood. In line with the model, we identify the channel as a key factor that affects whether or not information is noticed and that high visibility implies it is relevant to some audiences. Thus, we focus our studies broadly on what is visible in the online 
science communication landscape relating to climate change and healthy diets to help us understand which platforms and which communicators have the most effect on these discourses. Furthermore, we recognise that the channels that are visible may not be the same across different countries and that there will be local variation in platforms used. Thus, we chose to focus our study on three European countries representing different levels of science interest and communication contexts (the Netherlands, Serbia, and the U.K.).

\section{Methods}

This study formed part of a wider project, RETHINK

(https://www.rethinkscicomm.eu/) which is funded by the European Commission and exploring digital science communication across seven European countries (Italy, the Netherlands, Poland, Portugal, Serbia, Sweden, the U.K.) and four science topics: climate change, healthy diets, artificial intelligence and COVID-19.

Climate change was selected as a topic for this study because discourse about it incorporates a wide range of voices, including science sceptics. The polarised political debate around climate change may, therefore, include a range of non-traditional communicators, but the extent to which non-traditional communicators achieve high visibility within the debate is unknown. Miller and Dinan [2015], for example, highlight the role of think tanks and industry in climate change communication; while Cox and Schwarze [2015] explore the role of non-governmental organisations and pressure groups as climate change communicators. Petersen, Vincent and Westerling [2019] looked at the relative visibility of climate scientists and contrarians in online media, finding little difference in their visibility. These authors argue that digital media 'facilitates the production and mass distribution of assertive content by CCC [climate change contrarians]' [Petersen, Vincent and Westerling, 2019, p. 11].

Healthy diets was selected because food has a high profile within the wider digital health discourse [Cavusoglu and Demirbag-Kaplan, 2017]. Research is emerging to suggest that the digital discourse on healthy diets also contains a diverse range of communicators, including: industry [Pilgrim and Bohnet-Joschko, 2019; Klassen et al., 2018], health professionals, such as dieticians [Saboia et al., 2018; Helm and Jones, 2016] and those from a range of related professions including, alternative health practitioners, personal trainers, and 'culinary experts' [Chan, Drake and Vollmer, 2020; Saboia et al., 2018]. With both climate change and healthy diets, this research is intended to provide a more holistic picture of the actors communicating online and the platforms being used.

To allow a comparison of national differences, we focus here on three countries. These countries provide points of contrast, for example the Netherlands and the U.K. have similar levels of social media use $(64 \%-66 \%)$, while Serbians use social media less $(42 \%) .{ }^{1}$ In the Netherlands, WhatsApp is the most popular social media followed by Facebook and Instagram. ${ }^{2}$ Twitter is used less with around 1.13 million users in the Netherlands. In Serbia, Facebook is by far the most dominant social

\footnotetext{
${ }^{1}$ Active social media penetration in selected European countries and 2020, available from: https: / / www.statista.com/statistics / 295660/active-social-media-penetration-in-europeancountries / (accessed 22/10/2020).

${ }^{2}$ Social media usage in the Netherlands-statistics \& facts, available from: https: / / www.statista.com/topics/5524/social-media-in-the-netherlands / (accessed 22/10/2020).
} 
media platform used, accounting for over $80 \%$ of social media use. ${ }^{3}$ In the U.K., YouTube and Facebook are the dominant media with Twitter in fourth place after Instagram. Access to the Internet in the home is similar in the Netherlands and the U.K., with over $95 \%$ having access, and in Serbia slightly lower at $80 \%{ }^{4}$

Considering trust in science, $35 \%$ of people in the U.K. have a high trust in science, followed by the Netherlands at $28 \%$ and Serbia at $9 \%$ in national surveys. ${ }^{5}$ However, more people in the Netherlands have looked for scientific information in the past 30 days $(42 \%)$ compared with either Serbia (34\%) or the U.K. $(38 \%)$. A bigger difference however is seen when it comes to looking for information about health, where $60 \%$ of people in the Netherlands report seeking information, compared to $55 \%$ in the U.K. and $37 \%$ in Serbia.

Having set the scene for the research, we combined two methods to address the research questions. First, we conducted a scoping study to explore the actors communicating about climate change and healthy diets online in the Netherlands, Serbia and the U.K. We then conducted a survey in these countries to investigate which digital media platforms communicators use to reach their audiences.

The scoping study and the survey received ethical approval from The University of the West of England, Bristol.

\section{Scoping study}

We designed an online search scoping study protocol (see supplementary material) to find institutions and individuals that are highly ranked on Google and social media sites, hence likely to be highly visible in the digital landscape and so reflecting what online users would see. The protocol combined refined searches made with Google advanced search and with social media search tools. Google search was used since it is a well-known and broadly employed search engine, as well as enabling searches to be refined by language, country and domain [Brown, 2017]. We designed the protocol so that we could find communicators on websites, blogs, podcasts (via Google searches), Twitter, Instagram, Facebook, YouTube, Vimeo, Reddit and forums like Quora (via Google searches on social media sites and searches within social media sites). The protocol was replicable across different countries and topics, but flexible enough to allow each country to adapt the search terms and search method to their digital ecology. We piloted the protocol in Serbia and the U.K. to ensure it could be employed effectively by different researchers in potentially different digital landscapes. We used a browser that had not been employed by the researchers before and kept the search history and cache clean.

Data collectors based in each country conducted online searches of their respective digital landscape by applying the protocol from the $6^{\text {th }}$ of May to the $14^{\text {th }}$ of June 2019. Before searching for actors, data collectors in each country selected the digital

\footnotetext{
${ }^{3}$ Social Media Stats Serbia, available from: https: / gs.statcounter.com/social-media-stats/all/serbia (accessed 22/10/2020).

${ }^{4}$ Share of households in selected European countries with internet access in 2019. Available from: https:/ / www.statista.com/statistics/185663/internet-usage-at-home-european-countries / (accessed $22 / 10 / 2020)$.

${ }^{5}$ Wellcome Trust Global Monitor Report (2018), individual country level data. Available from: https:/ / wellcome.org/reports/wellcome-global-monitor/2018/appendix-country-level-data (accessed 22/10/2020).
} 
media platforms to explore. The research team in Serbia included the platform Krstarica in their search since it is a popular web portal in the country. The research team in the U.K. excluded Reddit and Quora from the search because it was not possible to filter the search results by country or distinguish communicators living in the U.K. from those in other countries using English to communicate.

The data collected included type of actor (e.g. journalist) and digital media platform(s) used by the actor. Every time we searched a platform and identified an actor, we verified whether this actor used other platform(s) to communicate about climate change or healthy diets. We included any other platform account of the same actor in the dataset only if it met the collection criteria. The protocol defined which types of actors to include: only individuals and institutions were included that shared non-academic content and content that was not specific to formal education with public audiences. Actors were considered only if they had an active digital media account (last used in 2018 or later) and if their content originated in the same country as that in which the search was being conducted.

We defined some categories of actors a priori to facilitate the data collection (e.g. activists); however, during the study additional categories were added (e.g. high-profile figures within an organisation). We categorised actors based on their self-description.

\section{Survey}

The questionnaire survey was developed as part of a larger study about the communication practices of science communicators in Europe. Here, we present results describing the channels respondents use to communicate, either on behalf of an organisation, in a professional capacity or in a personal capacity.

The questionnaire was designed in English and translated into Dutch and Serbian. It was distributed in the Netherlands, Serbia and the U.K. from the $30^{\text {th }}$ of September to the $1^{\text {st }}$ of November 2019. We distributed the questionnaire through official mailing lists, networks, associations, and societies of communicators (e.g. journalists, public relations officers, public event organisers), and via recommendation. We also sent the questionnaire to the individuals identified in the scoping study that had a public email address (39 from the Netherlands, 53 from Serbia, and 54 from the U.K.). This broad sampling strategy means it is not possible to calculate the response rate.

The survey was completed by 62 respondents from the Netherlands, 25 from Serbia and 122 respondents from the U.K. These respondents included professional and non-professional communicators (see Figure 1).

Results

This study explores the digital science communication landscape across three European countries: the Netherlands (NL), Serbia (RS) and the United Kingdom (U.K.). The results focus on the following themes: actors in the landscape, institutions and individual communicators, and the digital platforms used by the actors. 


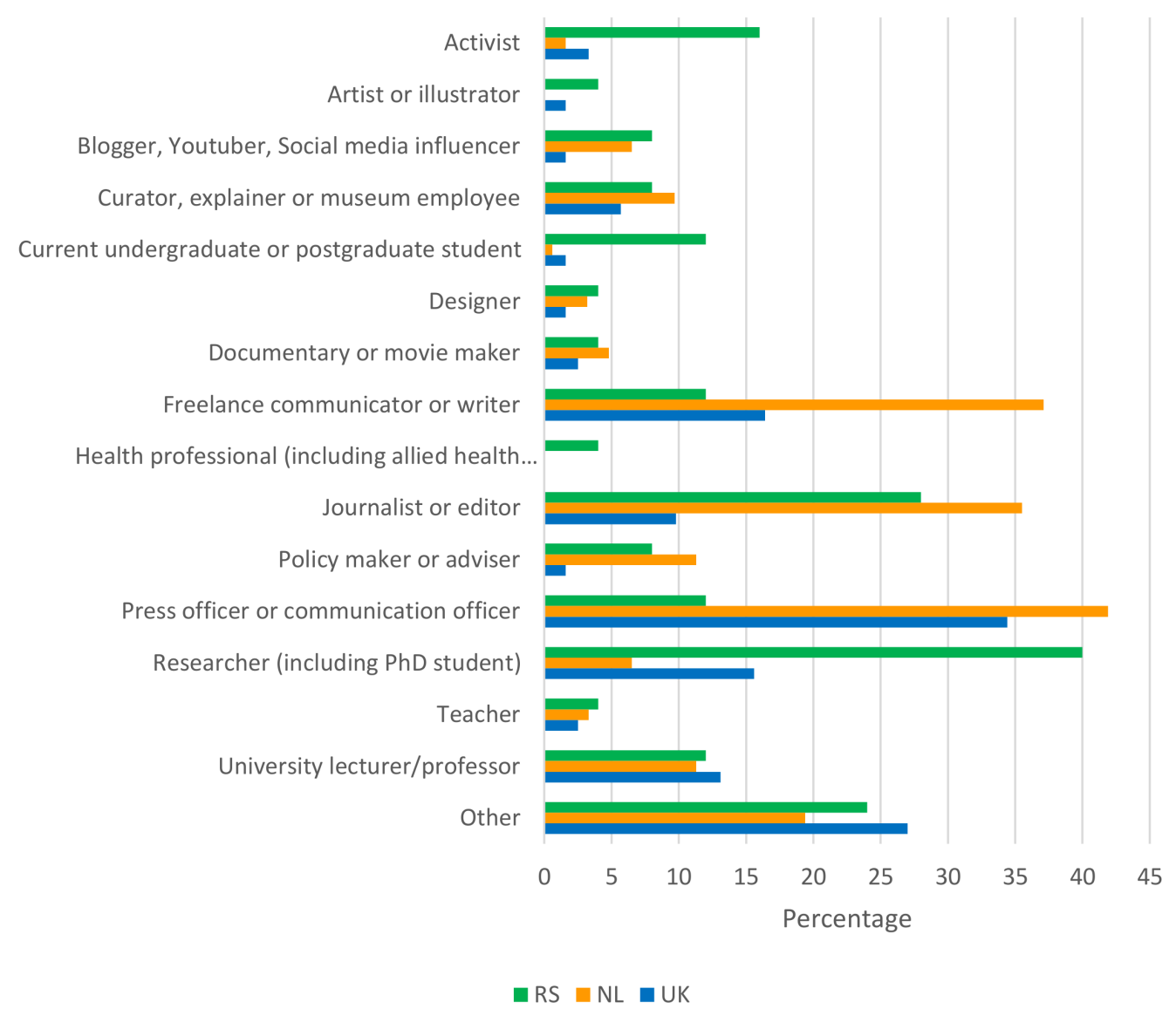

Figure 1. Percentage of respondents to the survey by type of actor across countries. Participants could select a maximum of 3 answers.

\section{Actors in the landscape(s)}

There are notable differences in the types of actors contributing to the discourses on climate change and healthy diets both between countries and topics (Figure 2). In the case of climate change, several actors are highly visible within the discourse of all three countries: NGOs, media and journalists play a significant role; to a smaller extent, non-professional communicators, activists and industry also contribute.

National differences emerge, however, with local and national government and policy makers, as well as scientists and scientific institutions contributing in the Netherlands and U.K., but largely absent in Serbia. Press officers, science museums and science centres were contributors in the Netherlands, while schools play a role only in Serbia and high-profile industry figures and artists were identified in the U.K. (Figure 2). Overall, there appears to be a wider range of organisations and individuals visible in the climate change discourse in the Netherlands and U.K., than in Serbia, where the discourse is dominated by media/journalists and NGOs.

The categories comprise: activists (individuals working on behalf of activist organisations or pressure groups), non-professional communicators (with no known tie to an organisation), governments (including local and national, and policy makers), health organisations and practitioners (including hospitals, public health bodies and individuals claiming a healthcare background), industry (e.g. green energy suppliers), media (including journalists), NGOs (including CSOs, 


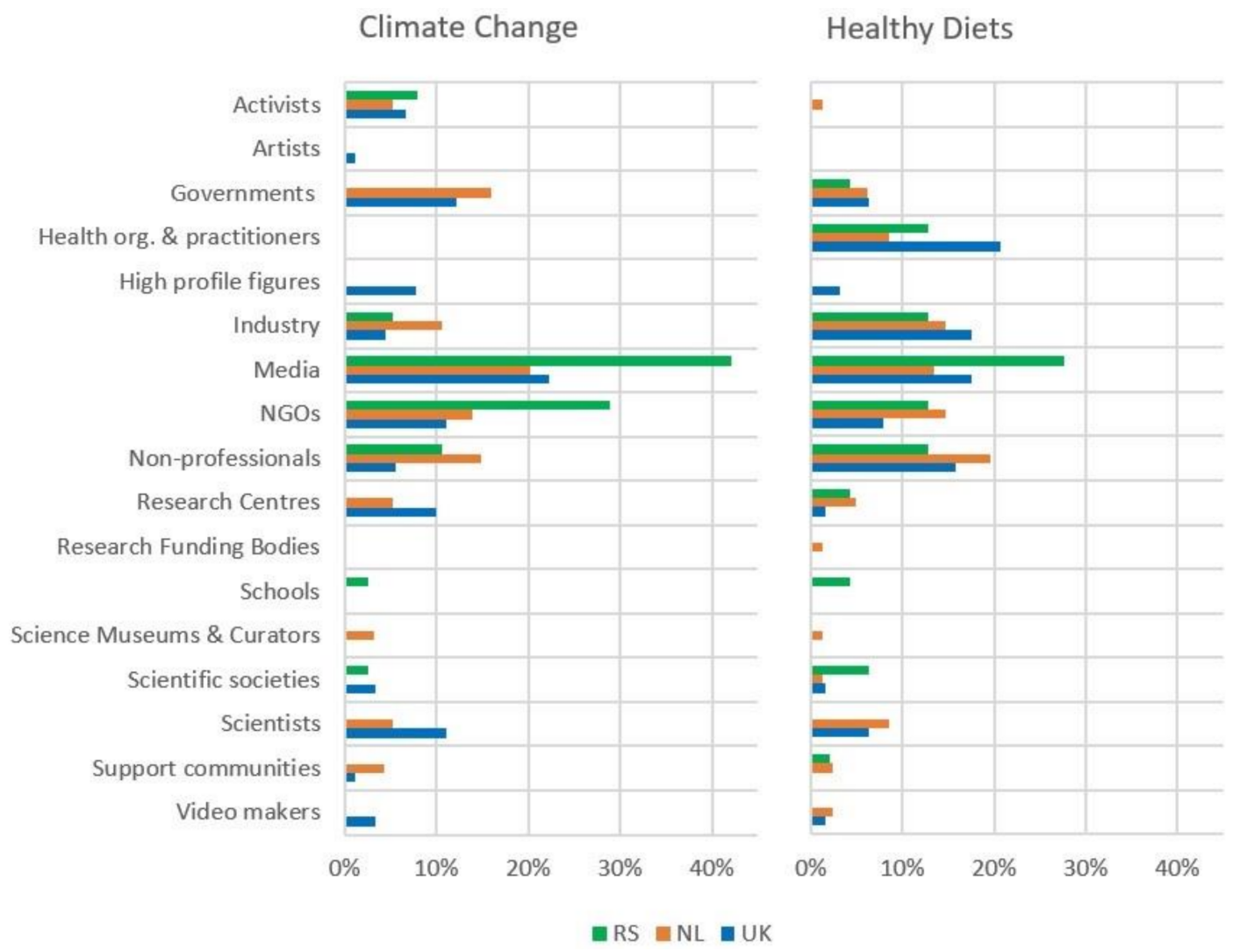

Figure 2. Highly visible actors in the climate change and healthy diets digital discourse.

Think Tanks and foundations), online video makers (without an obvious other background), research centres (including universities), funding bodies, schools, science museums (including science centres and curators), scientific societies, scientists (and researchers, but excluding health care professionals), support communities (e.g. weight loss groups).

The highly visible communicators change somewhat when considering the discourse on healthy diets in all three countries. Media organisations and NGOs are still prevalent across all three countries, and as with climate change this is particularly the case in Serbia. However, we see differences, with non-professional communicators, industry (e.g. supermarkets, supplement suppliers) and health practitioners and health organisations (particularly in the U.K.), more prevalent in the healthy diets landscape across all three countries. In contrast to climate change, activists are almost absent from communications about healthy diets (only identified in the Netherlands) and the government plays a relatively small role.

Looking at the different countries, the picture in the Netherlands is more mixed for the healthy diets topic than in either the U.K. or Serbia, with the healthy diets discourse dominated by five actor types: media and journalists $(20 \%)$, government and policy makers $(16 \%)$, non-professionals $(15 \%)$, NGOs $(14 \%)$, research organisations and scientists (15\%) and industry (11\%). Similarly, four types of communicators dominate the climate change discourse in the Netherlands: non-professionals (20\%), industry (15\%), NGOs (15\%), media and journalists (13\%). For both climate change and healthy diets, under $15 \%$ of the science communication content originates from 
non-professionals in the Netherlands. The scientific community is more visible in the healthy diets discourse in the Netherlands than in either Serbia or the U.K.

The climate change discourse in Serbia is dominated by media and journalists (42\%), NGOs (29\%) and to some extent, non-professional communicators (11\%). The healthy diets discourse is a more mixed ecology in Serbia, with media and journalists (28\%), followed by non-professional, health organisations and practitioners and NGOs (13\% each) also featuring. The scientific community (represented by research centres and scientists) is almost invisible in both discussions in Serbia, though scientific societies are visible to an extent in the healthy diets discourse.

In the U.K., the healthy diets discourse is dominated by four actors (industry; health organisations and practitioners; media and journalists and non-professional communicators), who together make up $65 \%$ of the highly visible communicators. This contrasts with the climate change discourse where we see a greater prominence of media/journalistic voices and expertise. $67 \%$ of the highly visible communicators in the U.K. on climate change are media and journalists $(22 \%)$, followed by scientists and research centres (21\%), government and policy makers (12\%) and NGOs (11\%). The scientific community is more visible in the climate change discourse in the U.K. than in either the Netherlands or Serbia.

Looking at the high-profile communicators, some differences between countries emerge in terms of affiliation. For the climate change discourse, institutions dominate in the Netherlands $(55 \%, n=94)$ and even more so for Serbia $(63 \%$, $n=38$ ). In contrast around half of U.K. communicators were identified as individuals (e.g. scientists, journalists) $(52 \%, n=90)$. Institutions dominate the healthy diets discourse in all three countries (NL, 55\%, $n=82$; RS, 74\%, $n=47$; U.K., $59 \%, n=63$ ).

\section{Who uses which platform?}

Looking first at climate change and the platforms on which content was located (Table 1), in the Netherlands, most actors were found on multiple platforms, though the choice of platform varied according to the actor, with the media and journalists, NGOs and government using YouTube; non-professional communicators and support communities using Reddit; and the media, industry, NGOs and activists also commonly using Facebook. Most communicators also used websites, blogs and Twitter in the Netherlands. Media organisations used the most diverse range of platforms in Serbia, followed by activists and NGOs. In the U.K., podcasts were made by scientific societies, research centres and universities, high profile figures and non-professional communicators; and websites were used by fewer communicators than in the Netherlands and Serbia. Most U.K. communicators used blogs, Twitter and Facebook to reach their audiences.

In relation to healthy diets, in the Netherlands and U.K., a range of types of communicators were found on most platforms, though only non-professional communicators used forums in the Netherlands (Table 2). Facebook was used by NGOs, media organisations, industry and non-professional communicators in the Netherlands and by media organisations, industry, high profile figures, health practitioners and non-professional communicators in the U.K. Podcasts were produced by media organisations, journalists, research centres and scientists in the Netherlands, 
Table 1. Media use by actors to communicate about climate change. Cells indicate number of actors identified using these platforms. Empty cells indicate no actors identified.

\begin{tabular}{|c|c|c|c|c|c|c|c|c|c|c|c|}
\hline & & Website & Blog & Facebook & Instagram & Twitter & YouTube & Krstarica & Forum & Reddit & Podcast \\
\hline \multirow[t]{9}{*}{ Serbia } & Activist & & 3 & 1 & 1 & 1 & & & & & \\
\hline & Industry & 2 & & & & & & & & & \\
\hline & Journalist & & 1 & & & & & 5 & & & \\
\hline & Media & 3 & 2 & 1 & & 1 & 2 & 1 & & & \\
\hline & NGO & 5 & 3 & 3 & & & & & & & \\
\hline & Non-professional & & & & 1 & & 1 & 2 & & & \\
\hline & School & & 1 & & & & & & & & \\
\hline & Scientific society & 1 & & & & & & & & & \\
\hline & $\begin{array}{l}\text { Note: Artists, Governm } \\
\text { Video makers were no }\end{array}$ & $\begin{array}{l}\text { ent, High } \\
\text { t identified }\end{array}$ & $\begin{array}{l}\text { file figu } \\
\text { any plc }\end{array}$ & $\begin{array}{l}\text { s, Policy ma } \\
\text { form in Serb }\end{array}$ & $\begin{array}{l}\text { kers, Researc } \\
\text { a }\end{array}$ & Centres, & science Mus & eums, Scien & ists, Supp & t Commu & ities and \\
\hline \multirow[t]{13}{*}{ Netherlands } & Activist & 2 & & 1 & 2 & 3 & & & & & \\
\hline & Government & 7 & & & & 1 & 1 & & & & \\
\hline & Industry & 7 & 1 & 2 & & 4 & & & & & \\
\hline & Journalist & 4 & & & & 3 & & & & & \\
\hline & Media & 10 & & 1 & 2 & 1 & 2 & & 1 & & \\
\hline & NGO & 8 & 2 & 5 & 4 & 5 & 3 & & & & \\
\hline & Non-professional & & 1 & & 1 & 2 & & & & 10 & \\
\hline & Policy maker & & 1 & & & 5 & & & & & \\
\hline & Research Centre & 3 & & & 1 & 2 & & & & & \\
\hline & Science Museum & 2 & & & 1 & 1 & & & & & \\
\hline & Scientist & & 1 & & & 4 & & & & & \\
\hline & Support community & & 2 & & 1 & & & & & 2 & \\
\hline & Note: Artists, High pro & file figures, & ientific & cieties and & Video makers & were not & dentified on & any platfor & $n$ in the $N$ & herlands & \\
\hline \multirow{15}{*}{$\begin{array}{c}\text { United } \\
\text { Kingdom }\end{array}$} & Activist & 1 & 1 & 5 & 4 & 5 & & & & & \\
\hline & Artist & & & & 1 & & & & & & \\
\hline & Government & 7 & & 1 & 1 & 1 & 1 & & & & \\
\hline & High profile figure & & 1 & & 1 & 7 & & & & & 1 \\
\hline & Industry & 2 & 2 & 1 & & 1 & & & & & \\
\hline & Journalist & & 1 & & & 10 & & & & & \\
\hline & Media & 9 & 1 & 3 & 1 & 4 & 1 & & & & \\
\hline & NGO & 7 & 6 & 9 & 6 & 9 & 4 & & & & \\
\hline & Non-professional & & 1 & 3 & 1 & 3 & & & & & 1 \\
\hline & Policy maker & & & 2 & & 4 & & & & & \\
\hline & Research Centre & 4 & 6 & 2 & & 3 & 1 & & & & 3 \\
\hline & Scientific society & & 2 & & & & & & & & 2 \\
\hline & Scientist & & 3 & & & 9 & & & & & \\
\hline & Support community & & & 1 & & & & & & & \\
\hline & Video maker & & & & & 1 & 3 & & & & \\
\hline
\end{tabular}

and by health practitioners, industry and non-professional communicators in the U.K. Instagram was used by non-professional communicators, industry, health practitioners, NGOs and research centres in the Netherlands and U.K. Only three platforms were identified in Serbia with all communicators making use of websites, blogs and YouTube.

\section{Practitioner survey}

We also explored platform use amongst practitioners to understand which platforms they use, who may be communicating on behalf of institutions or as individuals, and who may or may not be highly visible in the digital landscape. 
Table 2. Media use by actors to communicate about healthy diets. Cells indicate number of actors identified using these platforms. Empty cells indicate no actors identified.

\begin{tabular}{|c|c|c|c|c|c|c|c|c|c|}
\hline & & Website & Blog & Facebook & Instagram & Twitter & YouTube & Podcast & Forum \\
\hline \multirow[t]{12}{*}{ Serbia } & Government & 3 & & & & & & & \\
\hline & Health organisation & 3 & & & & & & & \\
\hline & Health practitioner & 2 & 1 & & & & & & \\
\hline & Industry & 5 & 1 & & & & 1 & & \\
\hline & Media & 12 & 1 & & & & 3 & & \\
\hline & NGO & 6 & & & & & 1 & & \\
\hline & Non-professional & 4 & 2 & & & & 1 & & \\
\hline & Research centre & 2 & & & & & & & \\
\hline & School & 2 & & & & & & & \\
\hline & Scientific society & 3 & & & & & & & \\
\hline & Support community & 1 & & & & & & & \\
\hline & \multicolumn{9}{|c|}{$\begin{array}{l}\text { Note: Activists, High profile figures, journalists, Policy makers, Research Funding Bodies, Science Museums, Scientists } \\
\text { and Video makers were not identified on any platform in Serbia }\end{array}$} \\
\hline \multirow[t]{30}{*}{ Netherlands } & Activist & & & & & 1 & & & \\
\hline & Government & 4 & & & & & & & \\
\hline & Health practitioner & 2 & 2 & & 1 & 1 & 1 & & \\
\hline & Industry & 6 & 3 & 1 & 5 & & 1 & & \\
\hline & Journalist & & & & & & & 2 & \\
\hline & Media & 5 & 1 & 1 & & & & 4 & \\
\hline & $N G O$ & 8 & & 1 & 2 & 6 & 1 & & \\
\hline & Non-professional & 7 & 2 & 3 & 6 & 3 & & & 1 \\
\hline & Policy maker & & & & & 1 & & & \\
\hline & Research centre & 3 & & & 1 & 1 & & 1 & \\
\hline & Research funding body & 1 & & & & & & & \\
\hline & Science Museum & 1 & & & & & & & \\
\hline & Scientific society & 1 & & & & 1 & & & \\
\hline & Scientist & & & & & 5 & 1 & 1 & \\
\hline & Support community & 1 & 1 & & & & & & \\
\hline & Video maker & & & & & & 2 & & \\
\hline & \multicolumn{9}{|c|}{ Note: Health Organisations, High profile figures and Schools were not found on any platform in the Netherlands. } \\
\hline & Government & 5 & & & & & & & \\
\hline & Health organisation & 3 & & & & & & & \\
\hline & Health practitioner & 1 & 3 & 6 & 9 & 5 & 2 & 4 & \\
\hline & High profile figure & & & 1 & 1 & 1 & & & \\
\hline & Industry & 3 & 6 & 3 & 3 & 2 & 1 & 1 & \\
\hline & Journalist & & & & & 1 & & & \\
\hline & Media & 10 & & 2 & & 2 & & & \\
\hline & NGO & 5 & 2 & & 1 & 1 & 1 & & \\
\hline & Non-professional & 2 & 3 & 9 & 6 & 6 & 3 & 1 & \\
\hline & Research centre & 1 & & & & & & & \\
\hline & Scientific society & 1 & & & & & & & \\
\hline & Scientist & & 1 & & 1 & 3 & & & \\
\hline & Video maker & & & & & & 1 & & \\
\hline
\end{tabular}




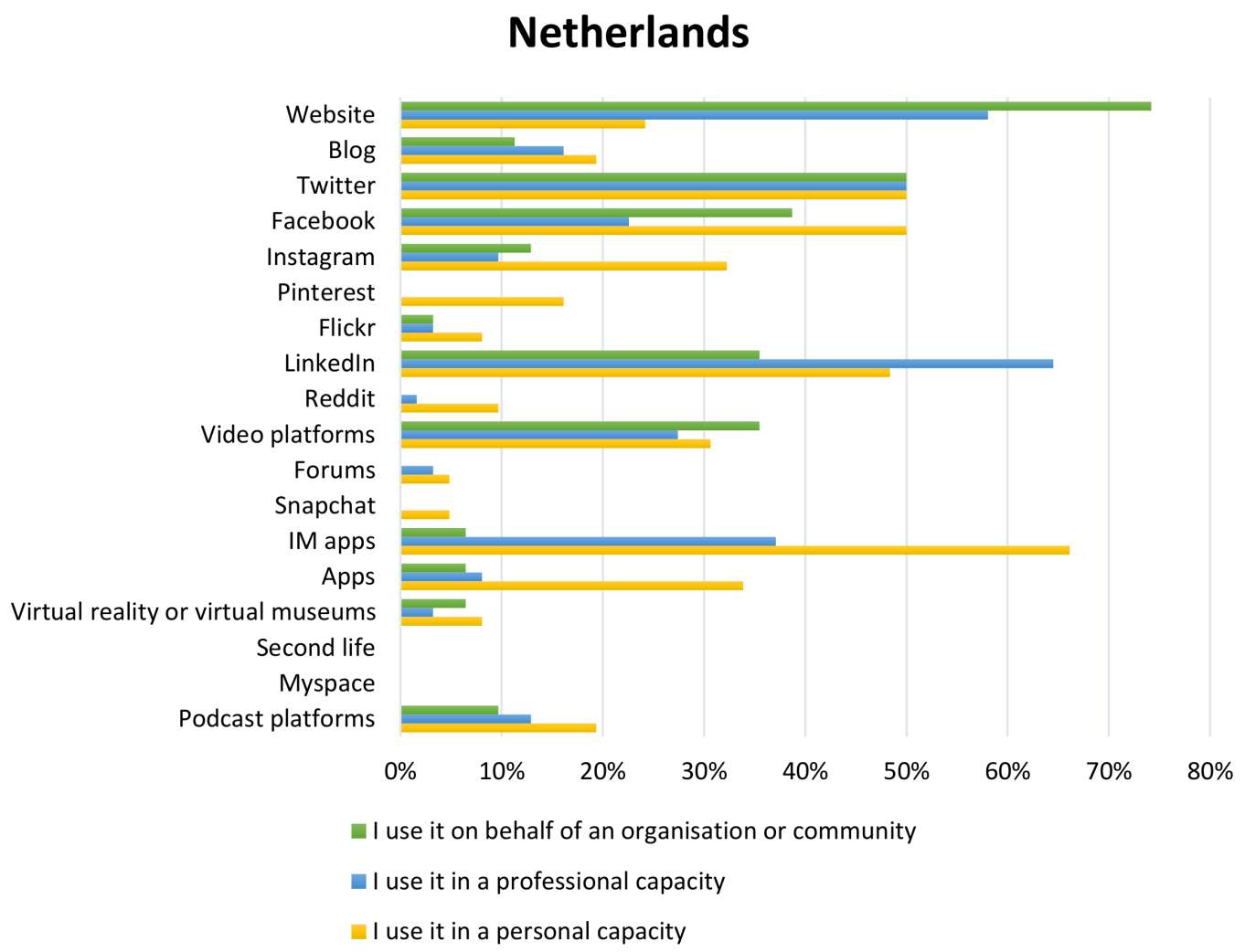

Figure 3. Organisational, professional and personal communication tools used in the Netherlands. Question text: What digital media outlets do you use to communicate science, technology and/or health topics? Tell us which outlets have you used on behalf of an organisation or community (e.g. university, company, association) and/or for yourself in the past 12 months (tick all that apply).

Looking at the survey results for the three countries, similarities and differences are evident in terms of the platforms used (Figures 3-5). Websites are widely used on behalf of an organisation in all three countries (NL $=74 \%$; RS $=76 \%$; U.K. $=76 \%$ ). Facebook $(\mathrm{NL}=39 \%$; RS $=36 \%$; U.K. $=45 \%$ ) and video platforms $(\mathrm{NL}=35 \%$; $\mathrm{RS}=24 \%$; U.K. $=41 \%$ ) were also widely used, while Twitter $(\mathrm{NL}=50 \%$; $\mathrm{RS}=16 \%$; U.K. $=60 \%$ ) and LinkedIn (NL $=35 \%$; RS $=12 \%$; U.K. $=25 \%$ ) were more widely used in the Netherlands and U.K. than Serbia. Blogs are only widely used in the U.K. on behalf of organisations (NL $=11 \%$; RS $=16 \%$; U.K. $=42 \%$ ), while Instagram was more widely used on behalf of organisations in Serbia and to a lesser extent in the U.K. (NL $=13 \%$; RS $=36 \%$; U.K. $=24 \%$ ).

We also asked about science communication undertaken in a professional capacity, for example freelance communicators or those undertaking communication activities which are not on behalf of an organisation. Websites remain a common communication platform ( $\mathrm{NL}=58 \%$; RS $=28 \%$; U.K. $=39 \%$ ), particularly in the Netherlands. LinkedIn, however, is amongst the most popular media used in a professional capacity $(\mathrm{NL}=65 \%$; RS $=24 \%$; U.K. $=54 \%$ ), alongside Twitter $(\mathrm{NL}=50 \%$; RS $=20 \%$; U.K. $=52 \%$ ) and video platforms $(\mathrm{NL}=27 \%$; RS $=16 \%$; $\mathrm{U} . \mathrm{K} .=33 \%$ ). Blogs are less commonly used in a professional capacity in the U.K. than on behalf of organisations, but are used at a similar level in both capacities in the Netherlands and Serbia (NL $=16 \%$; RS $=12 \%$; U.K. $=23 \%$ ). Facebook is less used professionally than on behalf of an organisation in all three countries 


\section{Serbia}

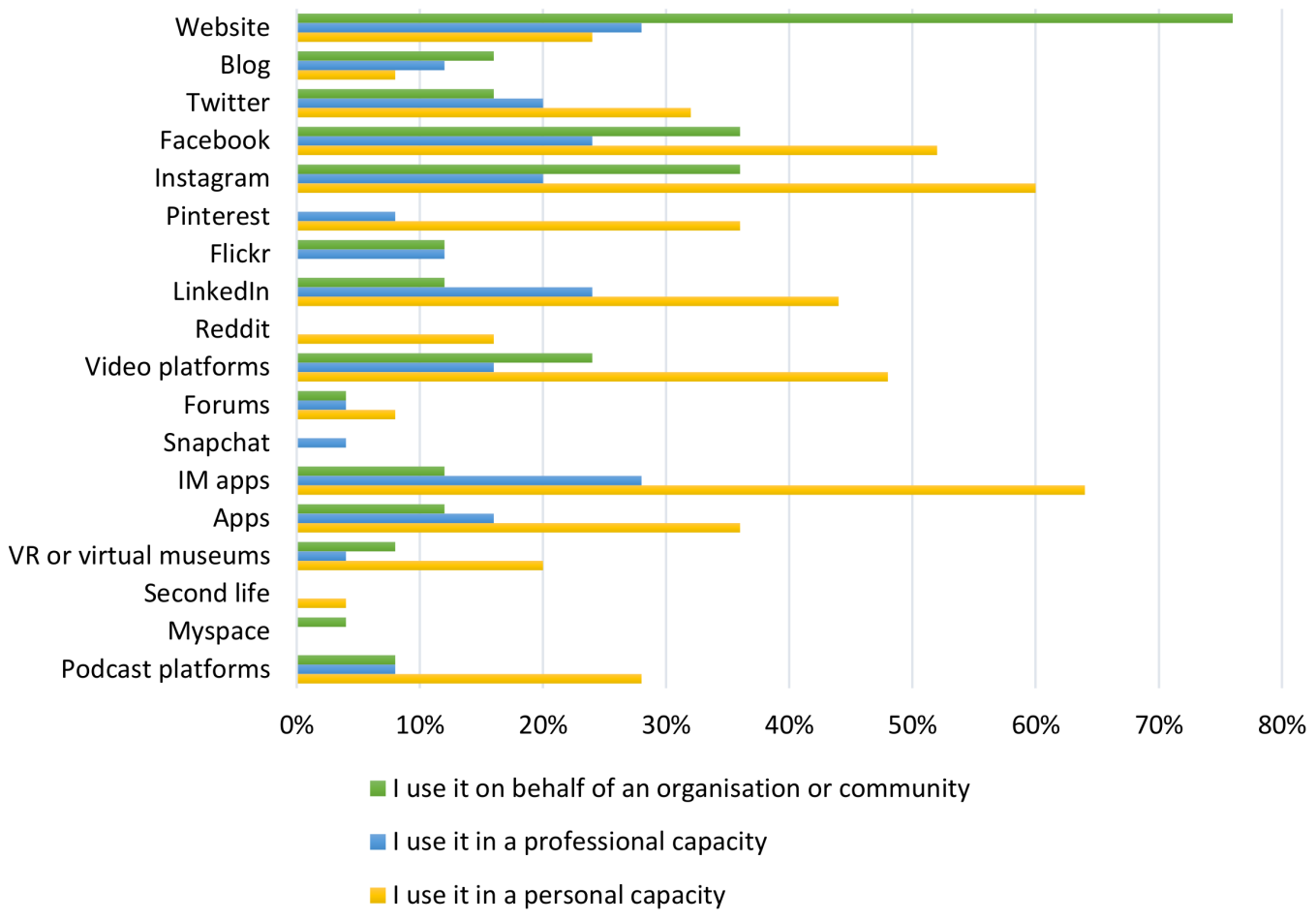

Figure 4. Organisational, professional and personal communication tools used in Serbia. Question text: What digital media outlets do you use to communicate science, technology and/or health topics? Tell us which outlets have you used on behalf of an organisation or community (e.g. university, company, association) and / or for yourself in the past 12 months (tick all that apply).

$(\mathrm{NL}=23 \% ; \mathrm{RS}=24 \% ; \mathrm{U} . \mathrm{K} .=20 \%)$. Instagram was used to a limited extent professionally, but more so in Serbia (NL $=10 \%$; RS $=20 \%$; U.K. $=13 \%$ ).

Finally, we asked survey respondents to indicate their use of communication platforms in their personal capacity. Here, the landscape changes. Websites are used, but much less frequently than on behalf of an organisation (under a quarter of respondents used websites to communicate science in a personal capacity) possibly due to the investment required in creating one. Personal use of Twitter $(\mathrm{NL}=50 \%$; RS $=32 \%$; U.K. $=51 \%$ ) is at levels similar to use on behalf of an organisation or professionally. Facebook (NL $=50 \%$; RS $=52 \%$; U.K. $=54 \%$ ), Instagram $(\mathrm{NL}=32 \%$; RS $=60 \%$; U.K. $=36 \%)$, Pinterest $(\mathrm{NL}=16 \%$; RS $=36 \%$; U.K. $=16 \%)$, instant messaging apps (NL $=66 \%$; RS $=64 \%$; U.K. $=58 \%$ ), and other types of apps (NL $=34 \%$; RS $=36 \%$; U.K. $=34 \%$ ) were more often used for communication in a personal capacity than in a professional/organisational capacity across all three countries. LinkedIn (NL $=48 \%$; RS $=44 \%$; U.K. $=33 \%$ ) is primarily used in a professional or personal capacity. Video (NL $=31 \%$; RS $=48 \%$; U.K. $=31 \%$ ) and podcast $(\mathrm{NL}=19 \%$; RS $=28 \%$; U.K. $=26 \%$ ) platforms were commonly used in all three countries. In all three countries, podcasts were more often used in a personal capacity than either a professional or organisational capacity.

Reddit and forums were not commonly used in either a professional or personal capacity, with only the U.K. having respondents who use Reddit on behalf of an 


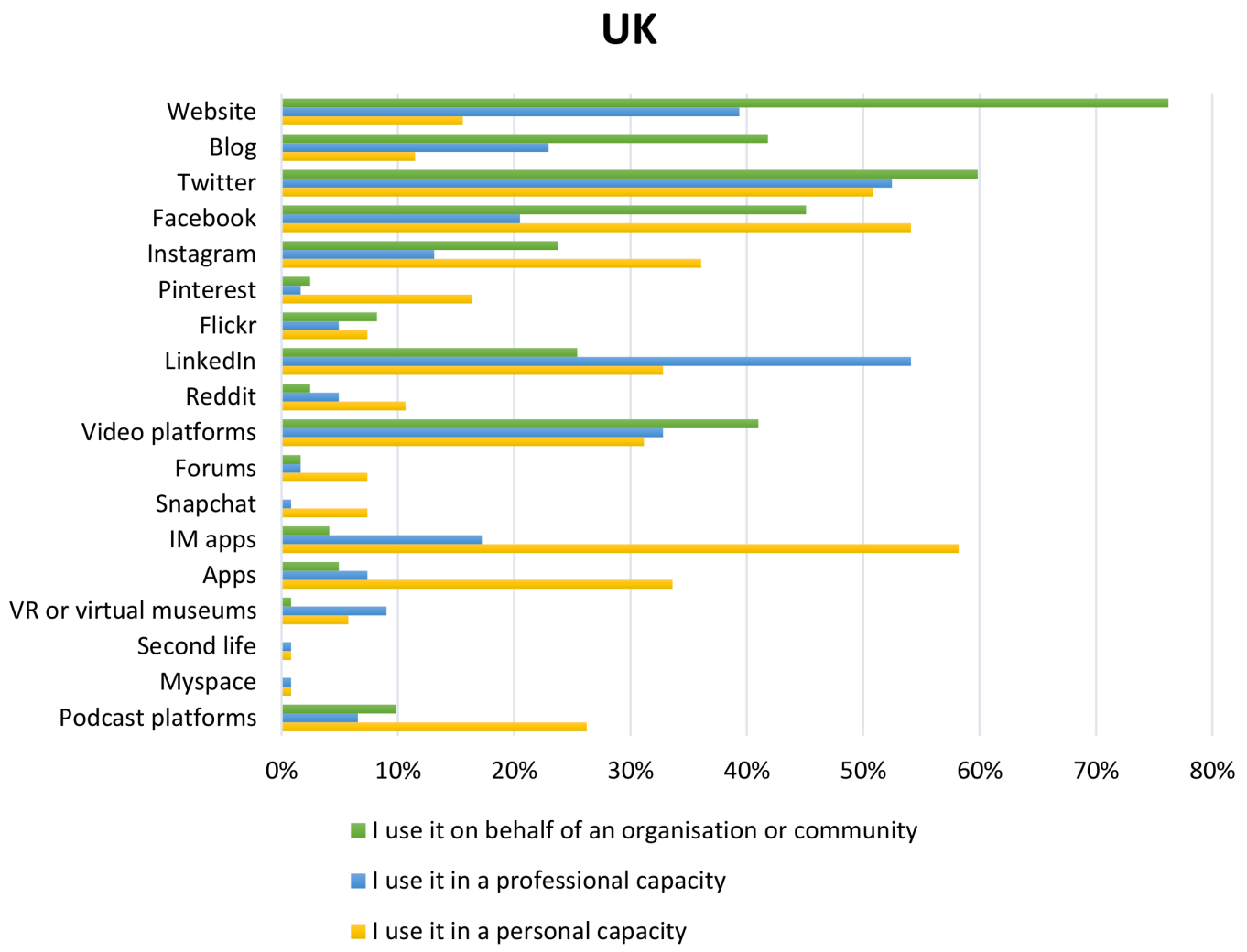

Figure 5. Organisational, professional and personal communication tools used in the U.K. Question text: What digital media outlets do you use to communicate science, technology and/or health topics? Tell us which outlets have you used on behalf of an organisation or community (e.g. university, company, association) and/or for yourself in the past 12 months (tick all that apply).

organisation and no professional use of Reddit mentioned by Serbian respondents. Second Life, Myspace and Snapchat were rarely used in a professional or personal capacity in all countries.

Here we return to address the research questions. First, we explore the media ecology in the three countries studied, with a particular focus on different actors between countries and between case studies. We then explore the platforms used to communicate about climate change and healthy diets and consider how these compare with responses to our survey, in light of Pearce et al.'s 2019 call for studies exploring a wider range of platforms.

1) What types of content producers are visible in the new media ecology of science communication, and do these vary between case study countries or between case study topics?

The data in this study suggest that the media ecology for digital science communication is, as suggested by Schäfer [2017], a space with a plurality of voices (see Figure 2). It characterises what was to a large extent only known anecdotally. Our data also suggest that the voices visible in this space vary between countries and topic areas. Notable, however, was the prevalence of media and journalists across all three countries and across both topic areas. Media and journalists may 
face increasing competition [Trench, 2007; Pearce et al., 2019], but they remain a prominent source of information and contributors to the broader public discourse. Another noticeable similarity between countries is the prevalence of nonprofessional communicators in the healthy diet discourse, perhaps indicating that the discussion here is more democratic [Murthy, 2018], allowing contributions from those who might not have access to legacy media, or it could be that diet is simply a more accessible subject, about which people gain knowledge and expertise throughout life giving them greater confidence to contribute. Further research could explore these facets of communication about healthy diets. NGOs are prominent in the climate change communications milieu in all three countries; environmental NGO's have a long history of influencing media agendas [Bakir, 2005] and are beginning to be recognised as alternative science communicators [Fähnrich, Riedlinger and Weitkamp, 2020]. Our findings support calls for further research into the 'impact, democratic legitimacy, and relevance of alternative science communication, and the challenges that alternative science communicators pose for science communication and society' [Fähnrich, Riedlinger and Weitkamp, 2020].

While we find similarities between the Netherlands, Serbia and the U.K., there are notable differences. In particular, the lack of contribution from healthcare professionals and organisations to the healthy diet discussion in the Netherlands and the absence of government and industry in both discourses in Serbia. In Serbia there was a distinct lack of visibility of research centres, universities and scientists. Across all three countries, scientists largely fail to achieve high visibility in these discourses, a finding also noted by Collins, Shiffman and Rock [2016]. Those scientists that we did find were often active on Twitter, and it is possible that we failed to locate scientists active on platforms like Facebook owing to the nature of the Facebook search engine. However, the study sought to identify those actors who are most visible in the communications landscape to online users, rather than capturing all those who are active. Some actors, such as individuals, may be placed at a disadvantage owing the nature of search engine algorithms, an issue worthy of further study.

Our survey data, which included a wide range of communication actors, including scientists (NL $=18 \%$; RS $=52 \%$, U.K. $=29 \%$ ) and press officers $(\mathrm{NL}=42 \%$; $\mathrm{RS}=12 \%$, U.K. $=34 \%$ ) suggests that this lack of visibility may not be due to a lack of trying and could be symptomatic of the challenges of organisational communication of science [Koivumäki and Wilkinson, 2020]. We also struggled to recruit policymakers to our survey (U.K. $=1.6 \%$; NL $=11 \%$; RS $=8 \%$ ), and while this could be an artefact of recruitment, it does suggest that this community does not necessarily identify as science communicators.

2) Which platforms are used to communicate about climate change and healthy diets in each of the case study countries?

To our knowledge, this is one of the few studies to have looked across platforms at the types of communicators contributing to discussion of scientific issues. When we consider the platforms used (see Table 1), we see a mixed ecology particularly for climate change communication. We also see changes in the platforms used depending on which actors are using them and about which topic. As seen in previous studies [Milani, Weitkamp and Webb, 2020; Bex, Lundgren and Crippen, 
2019; Didegah, Mejlgaard and Sørensen, 2018], Twitter is widely used in both discourses, but is more prevalent and used by more actors in the climate change discourse, particularly in the U.K. Twitter was widely used by survey respondents, though less so in Serbia, particularly in an organisational capacity. Although we found few highly visible scientists, those that we did encounter were also primarily found on Twitter, supporting the assertion of Collins, Shiffman and Rock [2016] that scientists may focus their efforts on this platform.

From our survey results, focussing on communication more broadly, we can see that many respondents use a wide range of platforms. However, these platforms are used in different capacities. For example, websites were primarily used in an organisational capacity (on average by $75 \%$ of respondents over all three countries) and much less frequently in a personal capacity; this mirrored the scoping study where $15 \%$ of Dutch website users were individuals, $3 \%$ of U.K. website users were individuals and no individuals were identified using websites in Serbia.

Facebook was widely used by survey respondents, though mainly in organisational (36-45\%) and personal (50-54\%), rather than professional (20-24\%) capacities. To our knowledge, this is the first study to explore the visibility of different types of actors on this platform. Most prior studies on Facebook have focused on the circulation of climate sceptic information [e.g. Bloomfield and Tillery, 2019] or fake news [Lutzke et al., 2019]. The scoping study suggests NGOs were visible on Facebook in all three countries, with activists and media evident in the U.K. and Serbia. Interestingly, industry was highly visible in the climate change discourse only in the Netherlands; whereas, non-professionals were only evident in the U.K. In contrast, the discussion of healthy diets on Facebook was dominated by non-professionals in the Netherlands, but was more diverse in the U.K., with non-professionals, health practitioners, industry and media most visible.

LinkedIn, a site which many users may associate with professional profiles and networking and was used predominantly in this capacity in the Netherlands and U.K., though it was primarily used in a personal capacity in Serbia. LinkedIn is a platform which has rarely been examined in existing research on science communication [Segado-Boj et al., 2019; LaPoe, Carter Olson and Eckert, 2017] suggesting this is worthy of further attention.

Instagram appears to be an emerging platform for science content. Our scoping study suggests that activists and NGOs dominate the discourse on climate change on Instagram in both the Netherlands and U.K., with activists and non-professional communicators visible in Serbia; to our knowledge this is the first study to explore the types of actors communicating about climate change on Instagram. Previous studies looking at diets/food on Instagram highlight the presence of industry in this discourse [Vassallo et al., 2018], which our study supports. In addition, we find non-professionals and NGOs in the Netherlands and non-professionals and health practitioners in the U.K., discussing healthy diets on Instagram. Instagram was primarily used in a personal capacity in all three countries, though it appears to be far more popular in Serbia than in either the U.K. or Netherlands. However, this had yet to translate to extensive organisational use (range 13-36\%, highest in Serbia) or professional use (10-28\%, lowest in the Netherlands). Our scoping study findings suggest that science communicators may not yet be particularly visible on 
this platform, complementing the findings of Jarreau, Dahmen and Jones [2019] who argue that science museums fail to make effective use of Instagram.

Studies of YouTube indicate a wide range of actors producing science-related video material [Muñoz Morcillo, Czurda and Robertson-von Trotha, 2016], a finding supported by our survey data which highlight the popularity of this platform for science communication; $70-80 \%$ of survey respondents were using video in either an organisational, professional or personal capacity to communicate science. Studies also suggest significant growth in YouTube [Bärtl, 2018], but that the platform is dominated by a few channels and it is challenging for new entrants to achieve visibility [Bärtl, 2018]. This may explain why video platforms were relatively less visible in the scoping study. Pinterest, Flickr, instant messaging apps and games were being used in a personal capacity and these are the only platforms where personal use outweighs professional use.

These results suggest a vibrant and mixed science communication digital ecology in all three countries, though visibility in relation to specific topic areas may vary. Referring back to the Koru model of science communication [Longnecker, 2016] the results suggest that, depending on the focus of the communication, communicators are considering the visibility of information, how it is relevant but also the channels via which visibility can be increased. Therefore, the platforms chosen vary across countries. As a user, the platform you use will affect which actors are visible, and therefore the types of messages you might receive. These actors also vary depending on which country you live in, as well as by the topics you explore. Our study did not explore how these platforms are used (whether as social media or social networks), and this would be a logical next step for research in this area.

\section{Limitations}

This was a scoping study of three countries within Europe and can only provide a snapshot of the range of actors that are contributing to discussions of healthy diet and climate change online over a specific period of time. Further research is necessary to fully examine the motivations, strategic intentions of communicators in their use of platforms, and the ways in which different platforms are used by different actors, as well as the impacts on audiences. In addition, this study explored which actors are most visible, but did not gather data about whether particular actors or platforms were more engaging for their audiences. For example, it would be interesting to explore the extent to which particular actors or platforms enable discussion amongst participants.

The scoping study data were collected and coded manually by one coder in each country. This could have resulted in some variations in approach and interpretation. However, we designed a straightforward protocol, with clear and unambiguous definitions for each category of actor and for collection criteria, minimising any variation in approach. Language differences between countries made intercoder tests of reliability impractical. The scoping study relied on Google and social media searches, which algorithms likely influenced the results. However, these results reflect what other Internet users see when seeking information online. The closed nature of platforms more commonly used as social networks, such as Facebook, in terms of permission being required to access specific groups, made 
exploration of the actors employing these platforms challenging in the scoping study. Likewise, in accessing potential survey respondents we used networks known to the project team. These networks tend to focus on those who identify as science communicators, making it challenging to reach many non-professional communicators or those who do not identify as science communicators.

Although we sought to recruit a wide range of respondents to our online survey, we received relatively few responses (particularly in Serbia). Thus, our data should be considered with caution, as it will reflect only those willing to participate in a survey that was promoted as being for science communicators. Many actors who contribute to the discourse on the topics of healthy diets and climate change may not recognise their role as science communication and may have chosen not to respond to the survey. The sample size may also vary based on the size of the science communication community within any one country. Nevertheless, the survey provides some first insights into the actors that contribute to these discourses across these three countries as well as the platforms that they choose to use. Further research could unpick these relationships in more detail at an individual country level.

Despite suggestions that traditional media are challenged by the variety of different new entrants into the digital landscape [Schäfer, 2017; Koivumäki and Wilkinson, 2020], our study suggests that media and journalists remain highly visible. These actors are effective at engaging with a variety of social media and social network platforms available for science communication. However, our study shows that they are joined by a range of new communicators including those referred to here as non-professional, a group of individuals who communicate on their own behalf and have no evident professional reason for communicating science. Within this mix we were surprised to find relatively few scientists and research institutions/universities achieving a high profile in the public sphere. This may reflect the challenge of attracting followers for example on platforms such as Twitter and Facebook, the subject matter selected as foci, or simply the timing of our study.

The scoping study suggests that there is scope for wider range of experts to contribute to discussions of healthy diets and climate change. The absence of communicators, such as scientists and universities/research centres, governmental organisations and policy makers from both the healthy diets and climate change discourses suggest there may be an opportunity for these actors to enter these spaces.

The survey results suggest that while scientists may not be highly visible across platforms, they are contributing to science communication. They could perhaps benefit from adopting techniques used by other actors on these platforms. An investigation of these techniques is beyond the scope of this paper, but warrants further consideration. Web analytics demonstrate that platform popularity varies with national context, with only Facebook amongst the most widely used platforms across all three countries we explored. ${ }^{6}$ The popularity of this platform with the

\footnotetext{
${ }^{6}$ Wellcome Trust Global Monitor Report (2018), individual country level data. Available from: https: / / wellcome.org/reports/wellcome-global-monitor/2018/appendix-country-level-data (accessed 22/10/2020).
} 
public suggests it may be a fertile place for science communication and both the scoping study and survey suggest it is widely used both professionally and personally for this purpose. In the Netherlands we see the most used science communication platforms mirroring wider social media use, though Twitter is more popular than might be expected. Serbia has strong parallels between personal, professional and organisational usage. YouTube, the most popular platform in the U.K., was less evident in our scoping study, though widely used by survey respondents. These findings suggest that science communicators are contributing to discussions on a wide range of platforms; that is, communicators appear to be going where the audience is, rather than expecting the audience to come to them.

References
Bakir, V. (2005). 'Greenpeace v. Shell: media exploitation and the Social Amplification of Risk Framework (SARF)'. Journal of Risk Research 8 (7-8), pp. 679-691. https://doi.org/10.1080/13669870500166898.

Bärtl, M. (2018). 'YouTube channels, uploads and views: a statistical analysis of the past 10 years'. Convergence 24 (1), pp. 16-32. https://doi.org/10.1177/1354856517736979.

Bex, R. T., Lundgren, L. and Crippen, K. J. (2019). 'Scientific Twitter: the flow of paleontological communication across a topic network'. PLoS ONE 14 (7), e0219688. https://doi.org/10.1371/journal.pone.0219688.

Bloomfield, E. F. and Tillery, D. (2019). 'The circulation of climate change denial online: rhetorical and networking strategies on Facebook'. Environmental Communication 13 (1), pp. 23-34. https://doi.org/10.1080/17524032.2018.1527378.

Brossard, D. (2013). 'New media landscapes and the science information consumer'. Proceedings of the National Academy of Sciences 110 (Supplement 3), pp. 14096-14101. https://doi.org/10.1073/pnas.1212744110.

Brown, C. C. (2017). Harnessing the power of Google: what every researcher should know. Santa Barbara, CA, U.S.A.: Libraries Unlimited.

Bruns, A. (2008). Blogs, Wikipedia, Second Life, and beyond: from production to produsage. 2nd ed. New York, NY, U.S.A.: Peter Lang.

Cavusoglu, L. and Demirbag-Kaplan, M. (2017). 'Health commodified, health communified: navigating digital consumptionscapes of well-being'. European Journal of Marketing 51 (11/12), pp. 2054-2079. https://doi.org/10.1108/EJM-01-2017-0015.

Chan, T., Drake, T. and Vollmer, R. L. (2020). 'A qualitative research study comparing nutrition advice communicated by registered dietitian and non-registered dietitian bloggers'. Journal of Communication in Healthcare 13 (1), pp. 55-63. https://doi.org/10.1080/17538068.2020.1749351.

Collins, K., Shiffman, D. and Rock, J. (2016). 'How are scientists using social media in the workplace?' PLoS ONE 11 (10), e0162680. https://doi.org/10.1371/journal.pone.0162680.

Cox, R. and Schwarze, S. (2015). 'The media/communication strategies of environmental pressure groups and NGOs'. In: The Routledge Handbook of environment and communication. Ed. by A. Hansen and R. Cox. Abingdon, U.K.: Routledge, pp. 73-85.

Davies, S. R. and Hara, N. (2017). 'Public science in a wired world: how online media are shaping science communication'. Science Communication 39 (5), pp. 563-568. https://doi .org/10.1177/1075547017736892. 
Didegah, F., Mejlgaard, N. and Sørensen, M. P. (2018). 'Investigating the quality of interactions and public engagement around scientific papers on Twitter'. Journal of Informetrics 12 (3), pp. 960-971.

https://doi.org/10.1016/j.joi.2018.08.002.

Fähnrich, B., Riedlinger, M. and Weitkamp, E. (2020). 'Activists as "alternative" science communicators - exploring the facets of science communication in societal contexts'. JCOM 19 (06), C01. https://doi .org/10.22323/2.19060301.

Fahy, D. and Nisbet, M. C. (2011). 'The science journalist online: shifting roles and emerging practices'. Journalism 12 (7), pp. 778-793. https://doi.org/10.1177/1464884911412697.

Hargittai, E., Füchslin, T. and Schäfer, M. S. (2018). 'How do young adults engage with science and research on social media? Some preliminary findings and an agenda for future research'. Social Media + Society 4 (3), pp. 1-10. https://doi.org/10.1177/2056305118797720.

Helm, J. and Jones, R. M. (2016). 'Practice paper of the Academy of Nutrition and Dietetics: social media and the dietetics practitioner: opportunities, challenges, and best practices'. Journal of the Academy of Nutrition and Dietetics 116 (11), pp. 1825-1835. https: //doi.org/10.1016/j. jand.2016.09.003.

Jarreau, P. B., Dahmen, N. S. and Jones, E. (2019). 'Instagram and the science museum: a missed opportunity for public engagement'. JCOM 18 (02), A06. https://doi.org/10.22323/2.18020206.

Kantar (2020). Public Attitudes to Science 2019. London, U.K.: Department for Business, Energy and Industrial Strategy.

Klassen, K. M., Borleis, E. S., Brennan, L., Reid, M., McCaffrey, T. A. and Lim, M. S. (2018). 'What people "like": analysis of social media strategies used by food industry brands, lifestyle brands, and health promotion organizations on Facebook and Instagram'. Journal of Medical Internet Research 20 (6), e10227. https://doi.org/10.2196/10227.

Koivumäki, K. and Wilkinson, C. (2020). 'Exploring the intersections: researchers and communication professionals' perspectives on the organizational role of science communication'. Journal of Communication Management 24 (3), pp. 207-226. https://doi .org/10.1108/JCOM-05-2019-0072.

LaPoe, V. L., Carter Olson, C. and Eckert, S. (2017). "“Linkedin is my office; Facebook my living room, Twitter the neighborhood bar": media scholars' liminal use of social media for peer and public communication'. Journal of Communication Inquiry 41 (3), pp. 185-206. https://doi.org/10.1177/0196859917707741.

Longnecker, N. (2016). 'An integrated model of science communication - more than providing evidence'. JCOM 15 (05), Y01. https://doi.org/10.22323/2.15050401.

Lutzke, L., Drummond, C., Slovic, P. and Árvai, J. (2019). ‘Priming critical thinking: simple interventions limit the influence of fake news about climate change on Facebook'. Global Environmental Change 58, 101964. https://doi.org/10.1016/j.gloenvcha.2019.101964.

Milani, E., Weitkamp, E. and Webb, P. (2020). 'The visual vaccine debate on Twitter: a social network analysis'. Media and Communication 8 (2), pp. 364-375. https://doi.org/10.17645/mac.v8i2. 2847.

Miller, D. and Dinan, W. (2015). 'Resisting meaningful action on climate change'. In: The Routledge Handbook of environment and communication. Ed. by A. Hansen and R. Cox. Abingdon, U.K.: Routledge, pp. 86-99. 
Muñoz Morcillo, J., Czurda, K. and Robertson-von Trotha, C. Y. (2016). ‘Typologies of the popular science web video'. JCOM 15 (04), A02.

https://doi.org/10.22323/2.15040202.

Murthy, D. (2018). Twitter: social communication in the Twitter age. 2nd ed. Cambridge, U.K.: Polity Press.

Pavelle, S. and Wilkinson, C. (2020). 'Into the digital wild: utilizing Twitter, Instagram, YouTube, and Facebook for effective science and environmental communication'. Frontiers in Communication 5, 575122. https://doi.org/10.3389/f comm.2020.575122.

Pearce, W., Niederer, S., Özkula, S. M. and Querubín, N. S. (2019). 'The social media life of climate change: platforms, publics, and future imaginaries'. Wiley Interdisciplinary Reviews: Climate Change 10 (2), e569. https://doi.org/10.1002/wcc.569.

Petersen, A. M., Vincent, E. M. and Westerling, A. L. (2019). ‘Discrepancy in scientific authority and media visibility of climate change scientists and contrarians'. Nature Communications 10, 3502. https://doi.org/10.1038/s41467-019-09959-4.

Pilgrim, K. and Bohnet-Joschko, S. (2019). 'Selling health and happiness how influencers communicate on Instagram about dieting and exercise: mixed methods research'. BMC Public Health 19, 1054.

https://doi.org/10.1186/s12889-019-7387-8.

Saboia, I., Pisco Almeida, A. M., Sousa, P. and Pernencar, C. (2018). 'I am with you: a netnographic analysis of the Instagram opinion leaders on eating behavior change'. Procedia Computer Science 138, pp. 97-104. https://doi.org/10.1016/j.procs.2018.10.014.

Schäfer, M. S. (2017). 'How changing media structures are affecting science news coverage'. In: The Oxford handbook of the science of science communication. Ed. by K. Hall Jamieson, D. M. Kahan and D. A. Scheufele. Oxford, U.K.: Oxford University Press, pp. 52-59. https://doi.org/10.1093/oxfordhb/9780190497620.013.5.

Schäfer, M. S. and Painter, J. (2021). 'Climate journalism in a changing media ecosystem: assessing the production of climate change-related news around the world'. Wiley Interdisciplinary Reviews: Climate Change 12 (1), e675. https://doi.org/10.1002/wcc. 675.

Scheufele, D. A. and Krause, N. M. (2019). 'Science audiences, misinformation, and fake news'. Proceedings of the National Academy of Sciences 116 (16), pp. 7662-7669. https://doi.org/10.1073/pnas. 1805871115.

Segado-Boj, F., Díaz-Campo, J., Fernández-Gómez, E. and Chaparro-Domínguez, M.-Á. (2019). 'Spanish academics and social networking sites: use, non-use, and the perceived advantages and drawbacks of Facebook, Twitter, LinkedIn, ResearchGate, and Academia.edu'. First Monday 24 (5). https://doi.org/10.5210/fm.v24i5.7296.

Spartz, J. T., Su, L. Y.-F., Griffin, R., Brossard, D. and Dunwoody, S. (2017). 'YouTube, social norms and perceived salience of climate change in the American mind'. Environmental Communication 11 (1), pp. 1-16. https://doi.org/10.1080/17524032.2015.1047887.

Su, L. Y.-F., Scheufele, D. A., Bell, L., Brossard, D. and Xenos, M. A. (2017). 'Information-sharing and community-building: exploring the use of Twitter in science public relations'. Science Communication 39 (5), pp. 569-597. https://doi.org/10.1177/1075547017734226. 
Trench, B. (2007). 'How the Internet changed science journalism'. In: Journalism, science and society: science communication between news and public relations. Ed. by M. Bauer and M. Bucchi. Basingstoke, U.K.: Routledge, pp. 133-142.

Vassallo, A. J., Kelly, B., Zhang, L., Wang, Z., Young, S. and Freeman, B. (2018). 'Junk food marketing on Instagram: content analysis'. JMIR Public Health and Surveillance 4 (2), e54. https: //doi .org/10.2196/publichealth.9594.

Wilkinson, C. and Weitkamp, E. (2013). 'A case study in serendipity: environmental researchers use of traditional and social media for dissemination'. PLOS ONE 8 (12), e84339. https://doi . org/10.1371/journal . pone.0084339.

- (2016). Creative research communication: theory and practice. Manchester, U.K.: Manchester University Press.

Authors

How to cite

\section{Supplementary} material
Emma Weitkamp is Co-director of the Science Communication Unit and Associate Professor in Science Communication. Her research interests explore narrative in science communication, considering both arts and media practice and the actors involved in science communication. She is Editor in Chief of JCOM.

E-mail: emma.weitkamp@uwe.ac.uk.

Elena Milani is a Research Fellow in the Science Communication Unit, her interests focus on digital science communication, with a particular interest in visual communication. E-mail: elena.milani@uwe.ac.uk.

Andy Ridgway is a Senior Lecturer in Science Communication and Programme Leader for the MSc in Science Communication. His research interests centre on science journalism and digital science communication.

E-mail: andy.ridgway@uwe.ac.uk.

Clare Wilkinson is Co-director of the Science Communication Unit and Associate Professor in Science Communication. Her research interests span the relationship between science and society, media representations of science and public engagement. E-mail: clare.wilkinson@uwe.ac.uk.

Weitkamp, E., Milani, E., Ridgway, A. and Wilkinson, C. (2021). 'Exploring the digital media ecology: insights from a study of healthy diets and climate change communication on digital and social media'. JCOM 20 (03), A02. https://doi.org/10.22323/2.20030202.

Available at https://doi.org/10.22323/2.20030202. 